JENNIFER SMITH AND CHARLOTTE O'CALLAGHAN

original

papers

\title{
Exploration of in-patient attitudes towards smoking within a large mental health trust
}

\begin{abstract}
AIMS AND METHOD
To explore the smoking habits of in-patients on psychiatric wards, their beliefs about the effects of smoking on health, and their attitudes towards hospital and government smoking policies. Face-to-face interviews with 135 in-patients were conducted.
\end{abstract}

\author{
RESULTS \\ A total of $54.1 \%$ of participants \\ smoked. Smoking was less prevalent \\ in those aged 65 years and older \\ $(P<0.001)$. Non-smokers were more \\ likely to believe smoking to be \\ harmful to health $(P=0.002)$. Overall, \\ $71.1 \%$ of the participants favoured \\ the existing smoking policy, with only \\ $3.0 \%$ wanting a complete ban on \\ smoking and $54.1 \%$ agreeing with \\ banning smoking in public places.
}

\author{
CLINICAL IMPLICATIONS \\ Further studies are warranted into \\ the views of in-patients elsewhere \\ and to see whether attitudes change \\ as trusts tighten their smoking \\ policies. Outdoor smoking areas may \\ need to be considered, although in \\ practice this may not be possible in all \\ trusts.
}

On 1 July 2007 all enclosed or substantially enclosed public places and workplaces became smoke free as required by The Health Act 2006. A temporary exemption for mental health units ends on 1 July 2008. Until then they may have a designated smoking room meeting specified requirements.

A very small number of studies exist on attitudes of staff towards smoking in psychiatric hospitals in the UK (Tarbuck, 1996; Stubbs et al, 2004), with even less information regarding patients' views. With impending government legislation and potential plans within Mersey Care NHS Trust to restructure the in-patient units, this was an ideal time to investigate this topic.

Mersey Care NHS Trust provides mental health services for the population of Liverpool, Sefton and Kirkby. At the time we surveyed its wards, the Trust had a general non-smoking policy. This entailed one or two smoking rooms on each ward with all other enclosed areas being non-smoking.

Our study aimed to explore the attitudes of inpatients across the General Adult and Old Age Directorates of the Trust towards the smoking policy and towards the perceived effects of smoking on health and well-being. We also aimed to examine any changes in smoking habits during hospital admission.

\section{Method}

A questionnaire was constructed following a review of literature on this topic (Senior, 1982; Stubbs et al, 2004; Willemsen et al, 2004) and based on the previous discussions with patients and ward staff. Structured and open-ended questions were included to generate both quantitative and qualitative data. The study protocol was then submitted to the Liverpool Research Ethics Committee Coordinator

During April and May 2006, face-to-face interviews were conducted with in-patients accepted for the study on ten general adult and three functional old age wards in the Trust hospitals. Patients were excluded from participation if their condition was too unstable. Written consent from each patient was obtained prior to interview.

The results were analysed using SPSS version 14.0 for Windows. Differences between smokers and nonsmokers, under 65-year-olds and over 65-year-olds, and those detained and informal were tested with the Pearson chi-squared and Fisher's Exact tests, both twotailed. Since there was a higher number of smokers among younger patients $\left(\chi^{2}=14.28, P<0.001\right)$, results pertaining to age were standardised according to current smoking habits. Ex-smokers were reclassified as nonsmokers to reduce the number of analyses.

\section{Results}

\section{Patient characteristics}

Out of 243 in-patients on the 13 wards, 135 were successfully interviewed (response rate 55.6\%; 52.6\% men, $47.4 \%$ women). The mean age of interviewees was 49.7 years (s.d. $=16.7$, range $18-86$ ), with $76.3 \%$ aged less than 65 years. A total of $68.1 \%$ of the participants were in informal care and $15.6 \%$ had been in hospital for at least 6 months.

\section{Smoking status}

The overall percentage of current smokers was $54.1 \%$, with $54.8 \%$ smoking prior to admission. No differences were found with respect to gender, Mental Health Act status or length of stay in hospital. However, more of those younger than 65 years old smoked than those aged 65 years and over $\left(63.1 \%\right.$ v. $25.0 \% ; \chi^{2}=14.28$, $P<0.001)$. Within the smoking group, $59.7 \%$ smoked at least 20 cigarettes per day (Table 1). 
Table 1. Comparison of questionnaire responses by gender, smoking status, Mental Health Act status, age or the length of stay in hospital

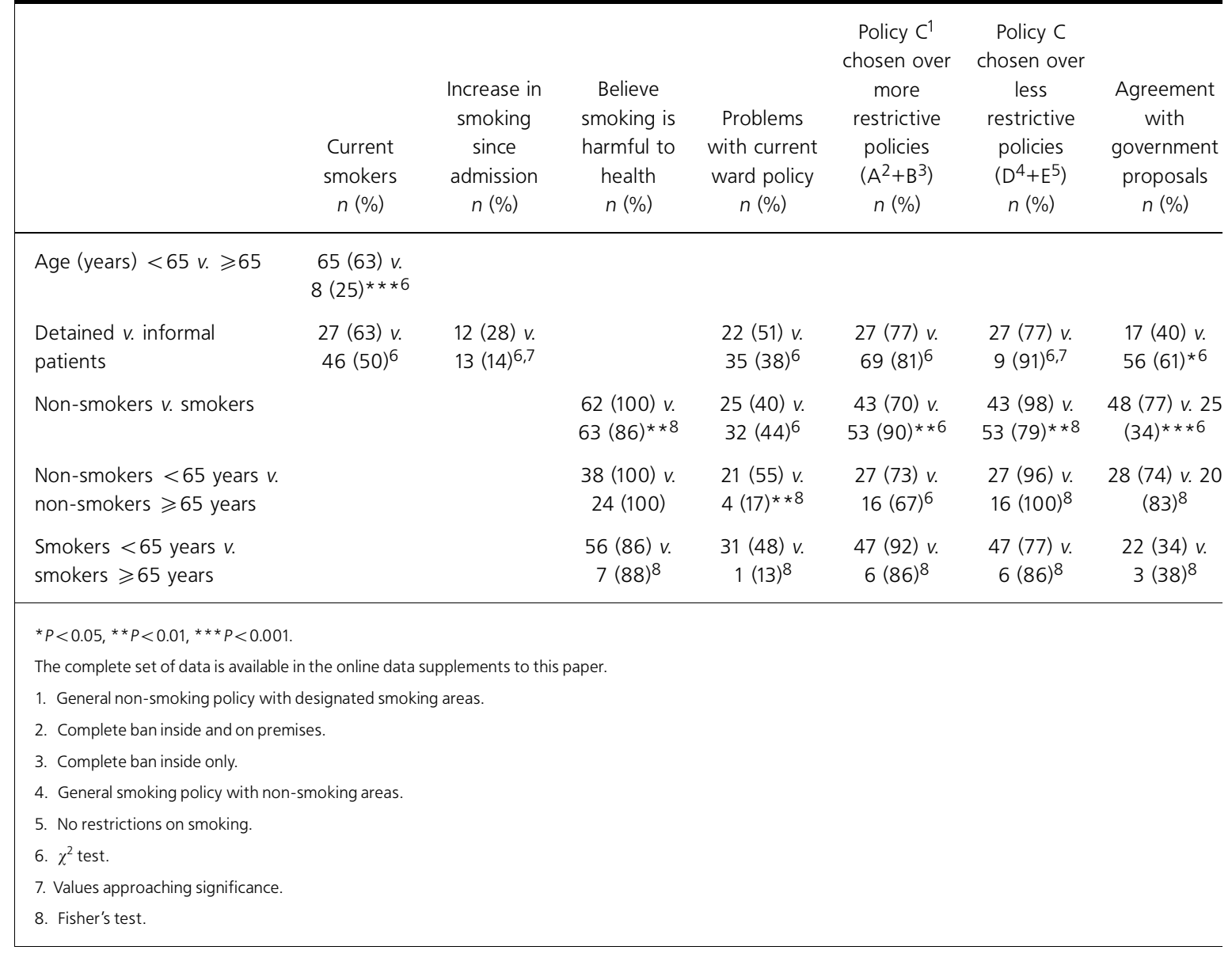

\section{Changes in smoking habits}

Although the reported overall rate of smoking remained fairly constant between pre-admission and the time of interviewing, $14.1 \%$ of the participants reported an increase and $23 \%$ a decrease of the habit. Two people reported re-starting smoking, two reported smoking for the first time in their lives and two reported both increasing and decreasing of smoking since admission.

To give reasons for increasing smoking, participants could choose those provided in the questionnaire 'boredom' ( $n=18)$, 'stress' $(n=12)$ and 'to socialise' $(n=6)$ - and cite their own, for example 'enjoying smoking' ( $n=1)$, 'craving more when unwell' $(n=1)$ and 'the environment' ( $n=1)$.

Reasons for decreasing smoking were the provided options: 'health concerns' $(n=17)$, 'financial reasons' $(n=7)$ and 'advice from staff' $(n=1)$, and other reasons like 'smoking restrictions on the ward' $(n=7)$, 'difficulty obtaining cigarettes' $(n=3)$, 'shouldn't smoke in hospital' $(n=2)$, 'want to give up smoking' $(n=1)$, 'pressure from relatives' $(n=1)$ and 'less stressed in hospital' $(n=1)$.

\section{Attitudes towards effects of smoking on health}

The number of participants who believed smoking to be harmful to health was $92.6 \%$, with smokers less likely to believe this than non-smokers (86\% v. 100\%, Fisher's $=9.17, P=0.002$ ). As much as $84.4 \%$ of the participants thought passive smoking to be harmful to health, with no difference between smokers and non-smokers, and $2.2 \%$ were not sure.

\section{Attitudes towards general non-smoking policy}

Fifty-seven participants (42.2\%) reported difficulties with the current general non-smoking policy. These results are shown in Table 2. Those non-smokers younger than 65 years old were more likely to report difficulties than nonsmokers aged 65 years and over (Fisher's $=9.11, P=0.003$ ).

\section{Preferred smoking policy within the Trust}

Only $3.0 \%$ chose complete ban inside and on premises as their preferred smoking policy, $14.1 \%$ supported complete ban inside only, $71.1 \%$ supported a general non-smoking policy with designated smoking areas, 7.4\% a general smoking policy with non-smoking areas and $4.4 \%$ would like no restrictions on smoking.

\section{Attitudes towards government proposals}

As much as $54.1 \%$ of participants in the study agreed with the government proposals to make all public places original papers 
original papers

\begin{tabular}{|c|c|c|c|c|}
\hline & $\begin{array}{c}n \text { (\% of total } \\
\text { sample) }\end{array}$ & $\begin{array}{c}\text { Smokers, } n \\
\text { (\% of smokers) }\end{array}$ & $\begin{array}{c}\text { Non-smokers, } \\
n \text { (\% of } \\
\text { non-smokers) }\end{array}$ & $\begin{array}{c}\text { Ex-smokers, } \\
n \text { (\% of } \\
\text { ex-smokers) }\end{array}$ \\
\hline No difficulties expressed & $78(57.8)$ & $40(54.8)$ & $28(63.6)$ & $10(55.6)$ \\
\hline People non-compliant with policy & $30(22.2)$ & $9(12.3)$ & $13(29.5)$ & $8(44.4)$ \\
\hline Concerns about the smell of smoke on themselves & $16(11.9)$ & $2(2.7)$ & $9(20.5)$ & $5(27.8)$ \\
\hline Unable to smoke where wishes to & $14(10.4)$ & $14(19.2)$ & 0 & 0 \\
\hline Breathing difficulties & $6(4.4)$ & $1(1.4)$ & $4(9.1)$ & $1(5.6)$ \\
\hline Unable to access certain rooms due to people smoking & $6(4.4)$ & $1(1.4)$ & $4(9.1)$ & $1(5.6)$ \\
\hline Inadequate standard of smoking area (cleanliness) & $5(3.7)$ & $4(5.5)$ & $1(2.3)$ & 0 \\
\hline Smoke infiltrating non-smoking areas & $5(3.7)$ & $1(1.4)$ & $2(4.5)$ & $2(11.1)$ \\
\hline Unable to watch TV when smoking & $4(3.0)$ & $4(5.5)$ & 0 & 0 \\
\hline Worsening of an existing medical condition & $2(1.5)$ & 0 & $2(4.5)$ & 0 \\
\hline Temptation to restart smoking & $1(0.7)$ & 0 & 0 & $1(5.6)$ \\
\hline Unable to smoke alone & $1(0.7)$ & $1(1.4)$ & 0 & 0 \\
\hline Headaches & $1(0.7)$ & 0 & $1(2.3)$ & 0 \\
\hline Nose irritation & $1(0.7)$ & 0 & $1(2.3)$ & 0 \\
\hline
\end{tabular}

non-smoking. Non-smokers were more likely to agree than smokers $\left(77 \%\right.$ v. 34\%, $\left.\chi^{2}=25.2, P<0.001\right)$ and informal patients were more likely to agree than detained patients $\left(61 \%\right.$ v. $\left.40 \%, \chi^{2}=5.37, P=0.020\right)$.

\section{Appendices (see online data supplements)}

1. Outline of the qualitative data generated from additional comments (Table DS1).

2. The complete data on the comparison of questionnaire responses (Table DS2).

\section{Discussion}

The higher smoking rates among younger people in this study were also found by the General Household Survey in the general population (Office for National Statistics, 2005a). That more smokers reported a decrease in smoking $(23.0 \%)$ than an increase $(14.1 \%)$ contrasted with our expectations, based on anecdotal evidence, that smokers might smoke more in hospital. Hence, we feel that the assumption that it would be particularly difficult to target non-smoking policies at psychiatric in-patients may not be justified.

While a high proportion (92.6\%) of the patients in this study recognised smoking to be harmful to health, we did not ascertain whether they appreciated the extent of the harm caused. In 2005 , only $48 \%$ of the population was aware that smoking is responsible for the most premature deaths in the UK (Omnibus Survey; Office for National Statistics, 2005b). The high percentage of patients $(84.4 \%)$ in our study recognising passive smoking as being harmful to health is compatible with the Omnibus Survey findings in 2005 when over $80 \%$ of participants thought second-hand smoking would increase a non-smoking adult's risk of lung cancer, bronchitis and asthma.

The finding that non-smokers younger than 65 years old reported more difficulties with separate smoking areas on the wards than non-smokers aged 65 and over may result from the greater proportion of smokers in the under-65-group. Alternative explanations may be different ward layouts, greater tolerance towards smoking among older people who grew up in a more smoking-permissive society and the fact that older people have been found to be more reluctant to express dissatisfaction with hospital policies (Calnan et al, 2003).

Although non-smokers and smokers were equally likely to have problems with the existing policy, the majority of complaints (80.8\%) were anti-smoking in nature. Nevertheless, despite these difficulties and knowledge of the harmful effects of smoking, the current general non-smoking policy was by far the most popular (71.1\%). This may indicate that in-patients on psychiatric wards are generally tolerant towards others. Alternatively, it may reflect the problem of social desirability, which commonly appears in surveys. In contrast with our study, a large Dutch survey of staff and patients across various psychiatric settings found that $45 \%$ of patients preferred a general non-smoking policy (Willemsen et al, 2004). However, only $8 \%$ preferred a complete smoking ban which compares with $11.8 \%$ in our study favouring the more restrictive policies.

There was a large difference observed in our study between those wanting a total smoking ban inside hospital buildings (14.1\%) and those supporting the government proposals of banning smoking in public places (54.1\%). This may reflect views that smoking policies should be more lenient in psychiatric units, as highlighted by the comments of eight patients. We found a 
considerably lower percentage of participants agreeing with the proposed ban on smoking in public places (54.1\%) than was seen in the public consultation on the Health Bill (89.6\%; Department of Health, 2005). Since our data shows that non-smokers were more likely to agree with this aspect of the legislation than smokers, this may be one explanation. Alternatively, our proactive method (face-to-face interviews) might have encouraged a wider variety of respondents.

There were some limitations to this study, namely volunteer bias, recall bias and slight environmental differences between wards. The number of hypothesis tests would have increased the likelihood of chance findings. Conversely, the small numbers in some groups may have meant insufficient power to detect additional significant differences. Lastly, ex-smokers were re-classified as nonsmokers although these two groups may have had different views.

Our study reinforces previous findings that smoking is more prevalent in patients on psychiatric wards than in general populations (de Leon et al, 1995; Meltzer et al, 1996; Lasser et al, 2000).

As the majority of in-patients, both smokers and non-smokers, felt there should be smoking areas within psychiatric units, can any appropriate compromise be reached there in view of the current legislation? One suggestion would be to ban smoking inside buildings in line with government legislation, but to have unenclosed smoking shelters outside the buildings, away from potential routes of entry of smoke into buildings. However, this may mean staff escorts being exposed to second-hand smoke. Furthermore, only patients well enough to leave the ward would be able to smoke. Another option could be outdoor smoking areas leading off from and visible from wards, but the problem of smoke infiltrating buildings remains and could necessitate the redesigning of buildings in many trusts.

It would be interesting to know if these results are mirrored elsewhere in the country and whether patients' views are changing following the implementation of tighter smoking policies within NHS trusts. It would also be worth evaluating the level of compliance with such policies.

\section{Acknowledgements}

We thank Dr Steven Lane, Senior Research Assistant at the Centre for Medical Statistics, University of Liverpool, for his help with analysis of the results, and Dr Robert Higgo, Consultant Psychiatrist, for his comments on the manuscript.

\section{Declaration of interest}

The authors were employed by Mersey Care NHS Trust at the time of the study.

\section{References}

CALNAN, M., WOOLHEAD, G. \& DIEPPE, OFFICE FOR NATIONAL STATISTICS P. (2003) Older people. Courtesy ～(2005a) General Household Survey entitles. Health Service Journal, 113, (http://www.statistics.gov.uk/ 30-31. StatBase/Product.asp? ?lnk=5756)

DE LEON, J., DADVAND, M., CANUSO, OFFICE FOR NATIONAL STATISTICS C., et al (1995) Schizophrenia and (2005b) Omnibus Survey: Smoking smoking: an epidemiological survey in a Related Behaviour and Attitudes state hospital. American Journal of (http://www.statistics.gov.uk/ Psychiatry, 152, 453-455. downloads/theme_health/ DEPARTMENT OF HEALTH (2005) Smoking2005.pdf).

Consultation on the Smokefree Elements of the Health Bill (http:// www.dh.gov.uk/en/Consultations/ Responsestoconsultations/ DH_4122129).

LASSER, K.,WESLEY BOYD, J., WOOLHANDLER, S., et al (2000) Smoking and mental illness. A population-based prevalence study. JAMA, 284, 2606-2610.

MELTZER, H., GILL, B., PETTICREW, M., et al (1996) Economic activity and social functioning of residents with psychiatric disorders. (OPCS Surveys of Psychiatric Morbidity in Great Britain Report No. 6). TSO (The Stationery Office).

SENIOR, S. L. (1982) Study of smoking habits in hospital and attitudes of medical staff towards smoking. Canadian Medical Association Journal, 126, 131-133.

STUBBS, J., HAW, C. \& GARNER, L. (2004) Survey of staff attitudes to smoking in a large psychiatric hospital. Psychiatric Bulletin, 28, 204-207.

TARBUCK, P. (1996) Smoking with patients: policy vs therapy. British Journal of Nursing, 5, 224-229. WILLEMSEN, M. C., GÖRTS, C. A., VAN SOELEN, P., et al (2004) Exposure to environmental tobacco smoke (ETS) and determinants of support for complete smoking bans in psychiatric settings. Tobacco Control, 13, 180-185.

*Jennifer Smith Specialist Registrar in Psychiatry, Assertive OutreachTeam, Arundel House Mental Health Resource Centre, Smithdown Health Park, Smithdown Road, Liverpool L15 2HE, UK， Charlotte O'Callaghan Specialist Registrar in Psychiatry, Older Peoples Services, Sir Douglas Crawford Unit, Mossley Hill Hospital, Liverpool, UK original

papers 